\title{
Study of role of metformin in management of polycystic ovarian syndrome
}

\begin{abstract}
Background: Insulin resistance is a common feature of Polycystic Ovarian Syndrome and is present in approximately $40-50 \%$ of this disorder. Response to insulin sensitisers appear to be maximal in women with disturbed insulin sensitivity. This argues in favour of its usefulness in patients with marked hyperandrogenism and insulin resistance. In this study, only metformin is used as an insulin sensitising drug.
\end{abstract}

Methods: The study analysed the usefulness of short term metformin therapy to reduce features of hyperandrogenism and hyperinsulinemia in PCOS patients. Out of 96 patients of PCOS, 48 cases were treated with metformin $(1500 \mathrm{mg} /$ day) for 3 months to 1 year and 48 controls were advised dietary modification and exercise. The changes in weight, BMI, menstrual cycles, ovulatory response and hormonal changes were compared in case and control.

Results: Study reveals marked improvements in all parameters amongst the cases who received metformin therapy.

Conclusion: Metformin may be a highly effective treatment protocol for the improvement of clinical, biochemical and hormonal profile in PCOS.

Keywords: Polycystic ovary, Metformin, Hyperinsulinemia, Hyperandrogenism
Volume 6 Issue I - 2017

Suresh Chandra Mandal, Sandip Lahiri, Pinaki Sarkar

Department of Obstetrics \& Gynaecology, West Bengal Health University, India

Correspondence: Suresh Mondal, Malda Medical College and Hospital,West Bengal Health University, Malda West Bengal, India,Tel 9734910276, Email sureshmondal77@gmail.com

Received: March 05, 2016 | Published: January 10, 2017

\section{Introduction}

Polycystic Ovarian Syndrome is a heterogeneous disorder affecting $5-10 \%$ of women of reproductive age. Insulin resistance plays an important role in dysregulation of folliculogenesis, anovulation and hyperandrogenemia in this disorder. Given the central role of insulin in the aetiology of PCOS, insulin sensitising agents have the potential to ameliorate insulin resistance and alleviate the spectrum of endocrine, meatabolic and reproductive abnormalities in women with PCOS.

Metformin, an insulin sensitising drug was given to PCOS patients for 3 months to one year with an aim to achieve the following

a. To decrease body weight and body mass index

b. To decrease the features of hyperandrogenism like decreased hair loss, diminished facial and body hair growth

c. Resumption of regular menstrual cycles

d. To achieve ovulation and pregnancy in infertile patients; to reduce fasting insulin and testosterone levels e. To reduce LH, FSH and LH: FSH to normal level.

\section{Material and methods}

The prospective study was carried out in Malda Medical College and hospital from 1st July 2014 to 31st May 201. 96 patients with menstrual irregularities, ultrasound finding of polycystic ovaries and anovulation on folliculometry along with raised or altered LH, LH: FSH, insulin, testosterone levels were selected for the study. 48 cases received metformin ( $1500 \mathrm{mg} /$ day) for 3 months to 1 year depending on the response. The changes in weight, BMI, menstrual cycles, ovulatory response, and hormonal changes were critically analysed. These results were compared with rest 48 control patients of the same weight and BMI range who were advised dietary modification and exercise and the efficacy of metformin was assessed.

\section{Result}

Tables 1-4

Table I Change in menstrual disorder after treatment between cases and control

\begin{tabular}{lllllll}
\hline Menstrual disorder & Total number & \multicolumn{3}{c}{ Cycle restored } & \multicolumn{2}{c}{ Cycle not restored } \\
\hline Hypomenorrhoea & Case & 4 & 4 & $100 \%$ & - & - \\
& Control & 4 & 2 & $50 \%$ & 2 & $50 \%$ \\
Oligomenorrhoea & Case & 30 & 22 & $73.3 \%$ & 8 & $26.7 \%$ \\
(35 d- 3 months) & Control & 30 & 10 & $33.3 \%$ & 20 & $66.7 \%$ \\
Oligomenorrhoea & Case & 14 & 10 & $71.4 \%$ & 4 & $28.6 \%$ \\
(3mths- 6mths) & Control & 10 & 2 & $20 \%$ & 8 & $80 \%$ \\
Amenorrhoea & Case & 0 & 0 & 0 & 0 & 0 \\
& Control & 4 & 0 & 0 & 4 & $100 \%$ \\
Total & & & 36 & $75 \%$ & 12 & $25 \%$ \\
& & & 14 & $29.2 \%$ & 34 & $70.8 \%$ \\
\hline
\end{tabular}


Table 2 Effect on Hirsutism on treatment in case \& control

\begin{tabular}{|c|c|c|c|c|c|c|}
\hline \multirow{2}{*}{ Effect } & \multicolumn{3}{|c|}{ Case } & \multicolumn{3}{|c|}{ Control } \\
\hline & \multicolumn{2}{|c|}{ No Hirsutism } & Hirsutism & \multicolumn{2}{|c|}{ No Hirsutism } & Hirsutism \\
\hline Before Treatment & 38 & $79.2 \%$ & $1020.8 \%$ & 38 & $79.2 \%$ & $1020.8 \%$ \\
\hline $\begin{array}{l}\text { After } \\
\text { Treatment }\end{array}$ & 38 & $79.2 \%$ & $10 \quad 20.8 \%$ & 38 & $79.2 \%$ & $1020.8 \%$ \\
\hline
\end{tabular}

Table 3 Evaluation of changes in mean values in different parameters amongst case \& control before and after treatment

\begin{tabular}{lllll}
\hline $\begin{array}{l}\text { Mean } \\
\text { parameters }\end{array}$ & $\begin{array}{l}\text { Case ( 48 ) } \\
\text { Before treatment }\end{array}$ & After treatment & $\begin{array}{l}\text { Control ( 48 ) } \\
\text { Before treatment }\end{array}$ & After treatment \\
\hline $\mathrm{Wt}(\mathrm{kg})$ & 53.29 & 51.86 & 53.17 & 52.63 \\
$\mathrm{BMl}(\mathrm{kg} / \mathrm{m} 2)$ & 23.01 & 22.36 & 23.05 & 23.66 \\
$\mathrm{LH}(\mathrm{mlu} / \mathrm{ml})$ & 19.63 & 7.34 & $14.0 \mathrm{I}$ & 13.59 \\
$\mathrm{LH}: \mathrm{FSH}$ & $2.32: \mathrm{I}$ & $1.07: 1$ & $2.09: 1$ & $2.19: 1$ \\
Fasting insulin $(\mathrm{mlU} / \mathrm{ml})$ & 12.48 & 7.33 & 10.35 & $10.5 \mathrm{I}$ \\
Testosterone & 0.68 & 0.54 & 0.63 & 0.64 \\
\hline
\end{tabular}

Table 4 Response of Metformin on ovulationc

\begin{tabular}{|c|c|c|c|c|c|}
\hline \multirow{2}{*}{$\begin{array}{l}\text { Duration of ovulation } \\
3 \text { Months to } 6 \text { Months }\end{array}$} & \multirow{2}{*}{$\begin{array}{l}\text { Total } \\
24\end{array}$} & \multicolumn{2}{|c|}{ Ovulation } & \multicolumn{2}{|c|}{ Anovulation } \\
\hline & & 16 & $66.7 \%$ & 8 & $33.3 \%$ \\
\hline 3-6 Months with Clomiphene & 4 & 4 & $100 \%$ & - & - \\
\hline 6 Months to 12 Months & 18 & 14 & $77.8 \%$ & 4 & $22.2 \%$ \\
\hline $6-12$ Months with Clomiphene & 2 & 2 & $100 \%$ & _- & - \\
\hline
\end{tabular}

\section{Discussion}

$75 \%$ cases in our study showed cycle restoration in contrast to $29.2 \%$ in control. Marked improvements in all parameters like weight, BMI, LH, LH: FSH, fasting insulin, and testosterone were found in cases who received metformin therapy. Metformin could not show any improvement in hirsutism score. 36 (75\%) out of 48 cases became ovulatory with metformin treatment. 6 of them needed additional clomiphene. $16(44.4 \%)$ cases ovulated with 3-6 months of metformin and $14(38.9 \%)$ needed them for 6-12 months.

\section{Conclusion}

Metformin either by weight reduction or by modest reduction of insulin and androgen level helps in restoration of menstrual cycles, ovulation and normalise LH: FSH, insulin and testosterone level as evident in our study. Metformin has also been found to potentiate the action of ovulation inducing drugs. Metformin may be considered as a useful drug reserved for infertile PCOS patients who are not responding to clomiphene citrate.

\section{Acknowledgments}

None.

\section{Conflicts of interest}

None.

\section{References}

1. Franks S. Polycystic ovary syndrome. N Engl J Med. 1995;333(13):853861.
2. Ehrmann DA, Rosenfield RL, Barnes RB, et al. Detection of functional ovarian hyperandrogenism in women with androgen excess. $N$ Engl $J$ Med. 1992;327(3):157-162.

3. Willis DS, Watson H, Mason HD, et al. Premature response to Luteinising Hormone of granulose cells from anovulatory women with polycystic ovarian syndrome. J Clin Endocrinol Metab. 1998;83(11):3984-3991.

4. Botwood N, Hamilton-Fairley D, Kiddy D, et al. Sex hormone binding globulin and female reproductive function. $J$ Biochem Mol Biol. 1995;53(1-6):529-531.

5. Moghetti P, Castello R, Negri C, et al. Metformin effects on clinical features, endocrine and metabolic profiles, and insulin sensitivity in polycystic ovary syndrome. J Clin Endocrinol Metab. 2000;85(1):139146.

6. Adams J, Polson DW, Franks S. Prevalence of polycystic ovaries in women with anovulation and idiopathic hirsutism. $\mathrm{Br}$ Med J (Clin Res Ed). 1986;293(6543):355-359.

7. Stein IF, Leventhal ML. Amenorrhoea associated with bilateral polycystic ovaries. Am J Obset Gynaecol. 1935;29(2):181-191.

8. Kahn CR, Flier JS, Bar RS, et al. The syndromes of insulin resistance and acanthosis nigricans $N$ Engl J Med. 1976;296(14):739-745.

9. Burghen GA, Givens JR, Kitabchi AE. Correlation of hyperandrogenism with hyperinsulinism in polycystic ovarian syndrome. J Clin Endocrinol Metabolt Gynaecol. 1980;50(1):113-116.

10. Swanson M, Sauerbrie EE, Cooperberg PL. Medical implications of ultrasonically detected polycystic ovaries. J Clin Ultrasound. 1981;9(5):219-222.

11. Nestler JE, Clore JN, Blackard WG. The central role of obesity (hyperinsulinemia) in the pathogenesis of the Polycystic ovary syndrome. Am J Obstet Gynaecol. 1989;161(5):1095-1097. 